Scientific Review - Engineering and Environmental Sciences (2021), 30 (1), 86-97

Sci. Rev. Eng. Env. Sci. (2021), 30 (1)

Przegląd Naukowy - Inżynieria i Kształtowanie Środowiska (2021), 30 (1), 86-97

Prz. Nauk. Inż. Kszt. Środ. (2021), 30 (1)

http://iks.pn.sggw.pl

DOI 10.22630/PNIKS.2021.30.1.8

Saif S. ALQUZWEENI, Afrah A. HASSAN, Rasha S. ALKIZWINI

University of Babylon, College of Engineering

\title{
A novel application of building demolition waste for removal benzene from aqueous solutions
}

Key words: building demolition waste, benzene, equilibrium, FTIR analysis

\section{Introduction}

The environment of the planet of Earth is deteriorating severely nowadays because of the increase in human activities, including industries and agriculture, which results in the production of enormous gaseous and liquid pollutants (Grmasha, Al-Sareji, Salman, Hashim \& Jasim, 2020; Zubaidi et al., 2020). For example, the cement industry pollutes the air with a wide range of gases and particulates (Kadhim, Sadique, Al-Mufti \& Hashim, 2020) that led to global warming (Salah, Abdulkareem et al., 2020; Zubaidi, Al-Bugharbee, Muhsin, Hashim \& Alkhaddar, 2020) and climate change (Salah, Ortega-Martorell et al., 2020). However, water sources are severely polluted due to the recent growth in industrial activities, where several contaminants, including petroleum hydrocarbons, have polluted many water bodies from various industries, such as textile, petroleum, and fertilizers industries (Hashim, Al-Saati, Hussein \& Al-Saati, 2018; Omran et al., 2019). Benzene is the commonest compound used for fractions of petroleum in a number of applications, such as raw materials in a number of industries and solvents in a number of industrial processes (Bakather, 2020); nevertheless, benzene is a toxic groundwater pollutant that has adverse impacts on the environment and hence endangers on the health of human. Based on the reports of the U.S. Environmental Protection Agency (EPA), benzene does not exceed $5 \mathrm{~g} \cdot \mathrm{L}^{-1}$. Therefore, safe, effective methods are needed to remove benzene from water. Benzene and organic matter were removed from water by a number of methods as wet air oxidation, photocatalytic degradation, and adsorption (Elsayed et al., 2017; Alquzweeni \& Alkizwini, 2020). Adsorption is one of the areas of surface chemistry that relies on the aggregation of contaminants called adsorbates on the 
surface of adsorbents (Bakather, 2020). The literature demonstrates that adsorption is the most powerful and widespread way to remove water contaminants, such as electro-chemical methods (Mohammed et al., 2020; Abdulhadi et al., 2021; Hashim, Shaw, AlKhaddar, Kot \& Al-Shamma'a, 2021), coagulation and electrocoagulation (Aqeel et al., 2020; Emamjomeh, Kakavand et al., 2020; Emamjomeh, Mousazadeh et al., 2020; Hashim, Kot et al., 2020), and hybrid methods (Alnaimi et al., 2020; Al-Marri et al., 2020; Zanki et al., 2020). Several adsorbents were used adsorb benzene and components from water, including beer bran (Legrouri et al., 2018), raw and thermally modified lignite (Aivalioti, Pothoulaki, Papoulias \& Gidarakas, 2012; Abdulla et al., 2020), and activated carbon (Perrich, 2018; Alyafei et al., 2020), and zeolite (Alenezi et al., 2020; Alhendal et al., 2020), natural adsorbents (Abdulraheem et al., 2020; Alenazi et al., 2020), and industrial byproducts (Hashim, Ewadh et al., 2020). However, various waste materials (e.g. biomass and sewage of sludge) were effectively used to minimize the cost of processing nanoporous carbon and controlling the accumulation of atmospheric waste materials (Abdulraheem et al., 2020). Adsorption may, therefore, be used to remove aromatic compounds dissolved in water. With the current trend of using methods that minimize losses and are sufficiently efficient, research has been conducted to evaluate the use of waste or by-products, in particular those generated by industrial processes among the various solid wastes. The prospect of using construction by-products (from the demolition process) as adsorbents would be a significant point for the present study to assess how suitable it is for removing benzene from aqueous solutions.

\section{Materials and methods}

\section{Adsorbent and contaminant}

The building materials waste from bricks used in this study has been collected and grinded, and then in the oven, drying is done for $24 \mathrm{~h}$ at $80^{\circ} \mathrm{C}$. The powder was placed in a container for further use. Distilled water is polluted with refined benzene $\left(\mathrm{C}_{6} \mathrm{H}_{6}\right)$ at room temperature (purity $>99.5 \%$, produced at a specific concentration by Sinopharm Chemical Reagent Co., Ltd.). This benzene's physical properties are $1,750 \mathrm{mg} \cdot \mathrm{L}^{-1}$ water solubility, 0.88 specific gravity, and 35 dynes per $1 \mathrm{~cm}$ interfacial tension (Elsayed et al., 2017).

\section{Characterization of building material waste}

Figure 1 shows the results of $\mathrm{X}$-ray diffraction, which indicates that $\mathrm{O}-\mathrm{H}$ ranges from 3,700 to $3,000 \mathrm{~cm}^{-1}$. The very strong and sharp band appearing at $3,644 \mathrm{~cm}^{-1}$ corresponds to calcium hydroxide stretching vibrations. The C-H stretching bands measure 3,300$-2,800 \mathrm{~cm}^{-1}$. In water solution, however, the $\mathrm{C}-\mathrm{H}$ vibration frequency is much lower than in non-polar solution. Extending vibration frequencies between hydrogen and other heteroatoms are 2,600-2,000 $\mathrm{cm}^{-1}$, including 2,250$-2,100 \mathrm{~cm}^{-1} \mathrm{Si}-\mathrm{H}$. Regions from 1,300 to $910 \mathrm{~cm}^{-1}$ also have skeleton $\mathrm{C}-\mathrm{O}$ and $\mathrm{C}-\mathrm{C}$ a contribution to vibration, providing additional molecular structural de- 

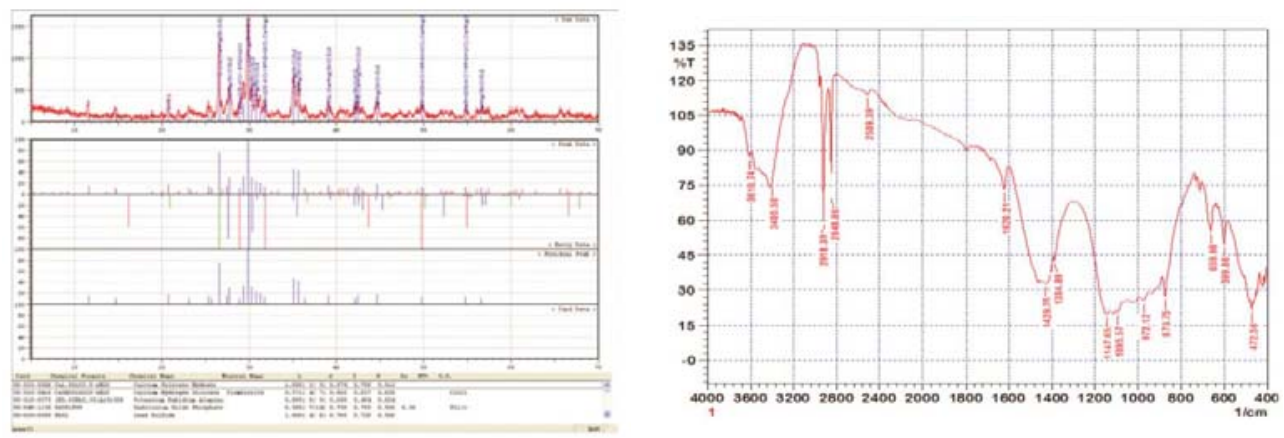

FIGURE 1. XRD and FTIR analysis for natural building material waste

tails relevant to higher frequency regions. Bands between 450 and $600 \mathrm{~cm}^{-1}$ are typical features of oxides not detected as major constituents. Due to the complex structure of building material waste, additional structural knowledge from this spectrum area is very difficult to obtain, as the bands characteristic of the various components overlap.

\section{Batch experimental study}

It is put in place to get the aforementioned single benzene equilibrium and kinetic data with prepared sorbents. This data will define the best-operating conditions such as initial $\mathrm{pH}$, sorbent dose, and shaking speed for some initial concentration $\left(C_{o}\right)$ that achieves the high performance of the process of treatment. Batch experiments are required for preparing a series of $250 \mathrm{~mL}$ flasks, and $100 \mathrm{~mL}$ of the contaminated water must be put in every flask with an initial $300 \mathrm{ppm}$ concentration. Different doses of sorbent were applied and the flasks were kept agitated for $180 \mathrm{~min}$ at $250 \mathrm{rpm}$. Then each flask solution was filtered to isolate the water from the solid particles. High-performance liquid chromatography can be used to calculate the residual concentration $\left(C_{e}\right)$ of benzene in the supernatant (HPLC, Shimadzu 2010 Japan). The principle of mass balance can be applied to locate the contaminant sorbed quantity per unit mass of the sorbent. Sorption analysis with $\mathrm{pH}$ levels of 3.0-7.0, contact time of 0-180 min and finally $C_{o}$ at $300-700 \mathrm{mg} \cdot \mathrm{L}^{-1}$ was performed. The amounts of pollutants sorbed onto the sorbent $\left(q_{e}\right)$ have been calculated for the best conditions as follows:

$q_{e}=\left(C_{o}-C_{e}\right) \frac{V}{m}$

where:

$V$ - volume of water in a flask [L],

$m$ - sorbent mass in a flask [g].

The adsorption isotherm is plotted between calculated $q_{e}$ and $C_{e}$.

\section{Equilibrium sorption process models}

The model of sorption is the relationship between the quantities of the chemicals sorbed on solids $\left(q_{e} \mathrm{mg} \cdot \mathrm{g}^{-1}\right)$ and final concentrations of the compound $\left(C_{e}\right.$ $\left.\mathrm{mg} \cdot \mathrm{L}^{-1}\right)$. At a certain temperature and 
$\mathrm{pH}$ values were determined; however, several isothermal models, including Freundlich and Langmuir, were fitted.

\section{Freundlich model}

The present model may cover multilayer sorption and heterogeneous surfaces but may, generally, be the following (Alquzweeni \& Alkizwini, 2020):

$q_{e}=K_{F} C_{e}^{1 / n}$

where:

$K_{F}$ - maximum quantities of contaminant sorbed on reactive material, $1 / n(<1)$ - indicated by the intensity of the sorption.

\section{Langmuir model}

Langmuir developed the following relationship for monolayer sorption and homogeneous surfaces (Alquzweeni \& Alkizwini, 2020):

$q_{e}=\frac{q_{\max } b C_{e}}{1+b C_{e}}$

where:

$q_{\max }-$ maximum capacity of adsorption $\left[\mathrm{mg} \cdot \mathrm{g}^{-1}\right]$,

$b$-intensity of contaminants to the solid phase.

\section{Kinetic models}

For the design of the appropriate sorption process, the rate of transfer is used from the watery to the solid phase. The following kinetic models predict this rate:

\section{Pseudo-first order model}

It has a formula to explain sorption rates as a function of time (Alquzweeni \& Alkizwini, 2020):

$\frac{\mathrm{d} q}{\mathrm{~d} t}=k_{1}\left(q_{e}-q_{t}\right)$

By applying $q_{t}=q_{e}$ at $t=t$ and $q_{t}=0$ at $t=0$, Eq. (2) is integrated to produce the following model:

$\ln \left(q_{e}-q_{t}\right)=\ln q_{e}-k_{1} t$ or $q_{t}=q_{e}\left(1-e^{-k_{1} t}\right)$

where:

$q_{t}, q_{e}$ - amounts of contaminant sorbed on the solid matrix in time $t\left[\mathrm{mg} \cdot \mathrm{g}^{-1}\right]$, $t$ - time of equilibrium [min],

$k_{1}-$ rate constant $\left[\mathrm{min}^{-1}\right]$.

\section{Pseudo-second order model}

The same energy of sorption for uninteracted sorbents and sorbed chemical species, as well as the contaminant's monolayer attached to the sorbent surface, are the general assumptions to guide this model as in Eq. (4):

$\frac{\mathrm{d} q}{\mathrm{~d} t}=k_{1}\left(q_{e}-q_{t}\right)^{2}$

where:

$k_{2}$ - rate constant $\left[\mathrm{g} \cdot \mathrm{mg}^{-1} \cdot \mathrm{min}^{-1}\right]$.

Eq. (5) is integrated under the same conditions as the previous model, and the equation will take the forms in Eq. (5):

$\frac{1}{\left(q_{e}-q_{t}\right)}=\frac{1}{q_{e}}+k_{2} t$ or $q_{t}=\frac{\mathrm{t}}{\left(\frac{1}{k_{2} q_{e}^{2}}+\frac{t}{q_{e}}\right)}$ 


\section{Results and discussion}

\section{Effect of adsorbent dosage}

The adsorbent dose effect on the adsorption of a fixed benzene concentration is shown in Figure $2 \mathrm{a}$. As the solvent dose increased over the range of 0.4-2.4 g per $100 \mathrm{~mL}$, the percentage of benzene sorbent increased reached $98 \%$. The number of available adsorption sites increases by raising the adsorbent dose, which increases the removal efficiency (Alquzweeni \& Alkizwini, 2020). Higher adsorption with the sorbent dose may also be due to increased surface area. These frequent findings with Langmuir's theories that the adsorbent particle is increasingly compatible with organic material with a growing amount of adsorbent particles per unit volume.

\section{Effect of the time of contact}

Determining the time of contact needed to achieve an equilibrium status takes into account the possible point of the batch study. Accordingly, as a function of the time of contact, the sorption of benzene on sorbents was controlled, and results were plotted in Figure $2 \mathrm{~b}$. Operational conditions include $C_{o}$, agitation rate of $300 \mathrm{ppm}$, and $250 \mathrm{rpm}$, respectively, adsorbent dose of $1.2 \mathrm{~g}$ added at room temperature to $100 \mathrm{~mL}$ of polluted water. Figure $2 \mathrm{~b}$ shows that the removal will increase in the early times of the rapid rate significantly with the contact time, and this rate slows after approximately $150 \mathrm{~min}$. The explanation for slower sorption may be the decline in vacant sites for adopting sorbent. $\mathrm{Ki}$ netic data shows that $1 \mathrm{~h}$ is sufficient for benzene removal. After this equilibrium period, there is no noticeable shift in the final concentration up to $180 \mathrm{~min}$ (Faisal \& Naji, 2019).

\section{Effect of initial pH}

Effects of the initial $\mathrm{pH}$ on benzene's adsorption by the adsorbent were measured at a $\mathrm{pH}$ range of 3.0-7.0. As shown in Figure 2b, the $\mathrm{pH}$ influences significantly on adsorption of benzene by the adsorbent of 3-6. This means the adsorbent has absorbed benzene. It can be shown that the adsorbent's adsorption capacity decreased rapidly to $\mathrm{pH} 7.0$. It can decrease the driving force of benzene, including the force of van der Waal to the adsorbent's active sites.

\section{Effect of initial benzene concentration}

The effect of the initial concentration on benzene's sorption efficiency within the range of $300-700 \mathrm{mg} \cdot \mathrm{L}^{-1}$ has been investigated. Figures $2 \mathrm{c}$ showed that the removal efficiencies of benzene on a sorbent at $(\mathrm{pH}$ 7.0) decreased from $(>90 \%)$ to lower values $(>50 \%)$ as a result of an increase in the $C_{o}$ within the range described. The primary explanation for this activity may be the presence of sufficient sites to absorb even more benzene from an aqueous solution. The benzene present in the solution is capable of interacting with lower concentrations of vacant binding sites and, therefore, has been high intake performance relative to higher rates. Thus, the treatment yield can be improved by diluting the water polluted with high benzene concentrations. 
a

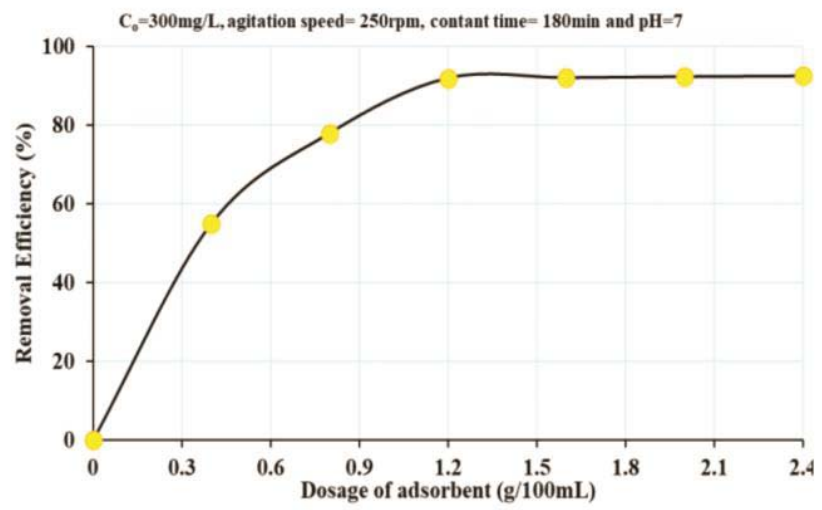

b

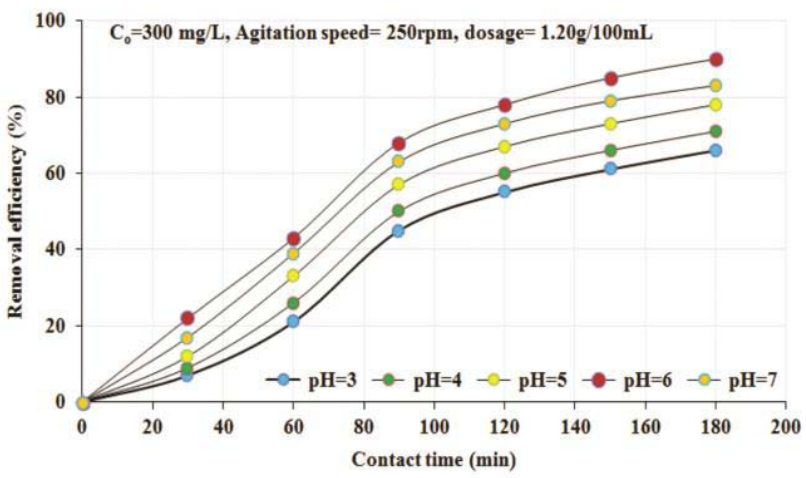

C

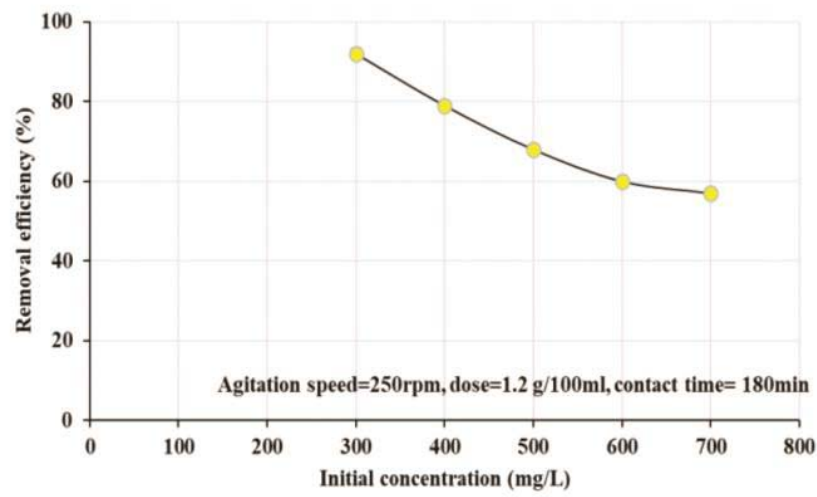

FIGURE 2. The relationship between benzene removal efficiency: $a$ - dose of the adsorbent; $b$ - time of contact, initial $\mathrm{pH} ; \mathrm{c}-$ initial concentration 


\section{Kinetic and isotherm analysis}

Figure 3 shows the pseudo-first, second-order, and Weber-Morris models that are fitted with kinetic data. For this reason, Microsoft Excel 2016 used the nonlinear regression approach to find the models' constants. The benzene sorption is compatible with (pseudo-first order kinetic) model. This indicates that physical sorption is the primary Sorption mechanism under consideration (Alquzweeni \& Alkizwini, 2020). Sorption mechanisms are difficult to characterize based on the previously described kinetic models. This function was thus performed based on (intra-particle diffusion) model concepts. As shown in Eq. (8), the model would be represented empirically where the sorbed quantity changing as a function of $t^{0.5}$ instead of $t$.

$q_{t}=k_{\mathrm{int}} t^{0.5}+C$

where:

$k_{i}$ - constant rate of stage $i\left[\mathrm{mg} \cdot \mathrm{g}^{-1} \cdot \mathrm{h}^{-0.5}\right.$ ], and is equal to the related slope of $q_{t}$ to $t^{0.5}$.

The intercept for stage $i$ is also expressed by the value of $c_{i}$ and reflects the boundary layer's thickness. This implies the greater boundary layer effect can be recognized with the greater intercept value. The intra-particle diffusion occurs if the relationship is associate linearly between $q_{t}$ and $t^{0.5}$. If the linear plot passes through the origin, the rate-limiting mechanism is defined as the only intra-particle diffusion. Otherwise, other processes of intra-particle diffusion must be considered. The adsorption mechanism is usually considered to include: (i) the mass transfer of adsorbents from bulk to the particulate surface, (ii) surface adsorption, finally (iii) intra-particle diffusion of the adsorbed molecules to an adsorption site through a pore diffusion and/or surface diffusion mechanism. Step (ii) is always presumed to be extremely fast; hence the adsorption of large molecules with long periods of contact to equilibrium is often considered to be regulated by diffusion through external film resistance and/or internal mass transfer of diffusion or intra-particle diffusion. A classical method for evaluating whether intra-particle diffusion regulates an adsorption mechanism is to plot the amount adsorbed versus the square root of time $\left(t^{0.5}\right)$; when the plot is linear and passes through the origin, it implies that the adsorption rate is regulated by intra-particle diffusion. So, Figure 3 shows the amount of benzene adsorbed for the adsorbents as a function of $t^{0.5}$. It can be shown that the experimental data are satisfactorily fitted by the intra-particle diffusion model, obtaining a linear section that does not pass through the origin, suggesting that benzene adsorption on these adsorbents is not controlled by intra-particle diffusion. Sorption tests are carried out for various concentrations under conditions of $\mathrm{pH} 7.0$, dose $=$ $=1.2 \mathrm{~g}$ per $100 \mathrm{~mL}$, speed of $250 \mathrm{rpm}$, and contact time of $3 \mathrm{~h}$. Freundlich and Langmuir isotherms are shown graphically in Figure 3, and the table lists their constants, which were determined using non-linear fitting of these models with sorption measurements using the Microsoft Excel 2016 Solver option (Alquzweeni \& Alkizwini, 2020). Based on Figure 3 and determination coefficient $\left(R^{2}\right)$ in the table, in the definition of sorption measurements, Freundlich model is better than Langmuir one. 
a

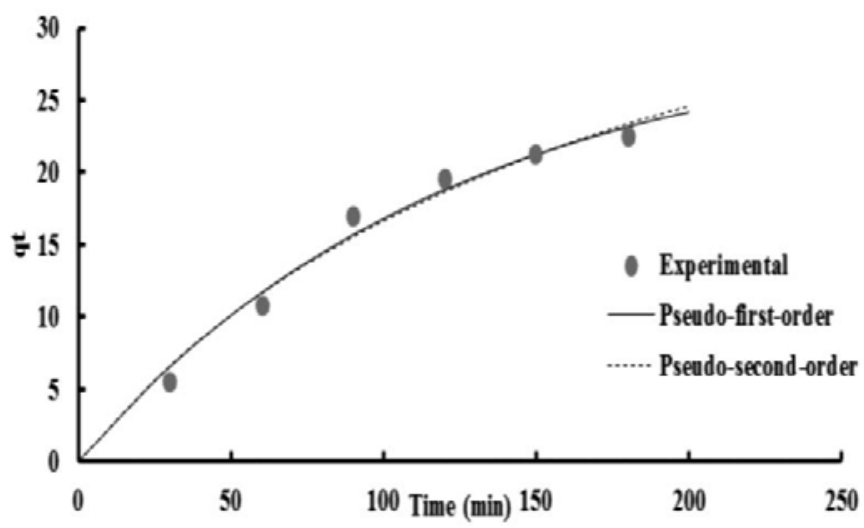

b

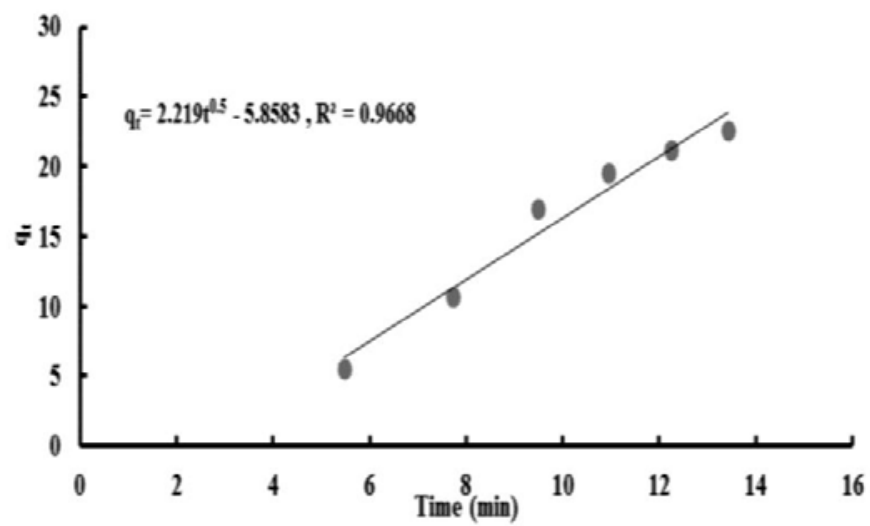

C

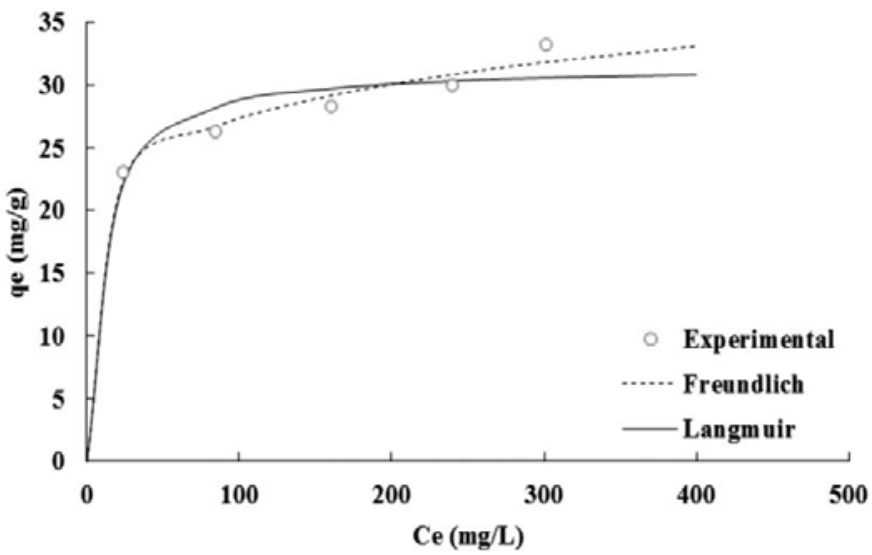

FIGURE 3. Experimental data on sorption fitted with (a) pseudo-first, pseudo-second order models, (b) intra-particle diffusion model, and (c) the isotherm models for the benzene's sorption 
TABLE. Isotherm and kinetic modals' constant for benzene's sorption

\begin{tabular}{|c|c|c|c|}
\hline & Model & Parameter & Value \\
\hline \multirow{8}{*}{ 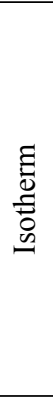 } & \multirow{4}{*}{ Freundlich } & $K_{F}\left[\mathrm{mg} \cdot \mathrm{mg}^{-1}\right]\left[\mathrm{L}^{2} \cdot \mathrm{mg}^{-1 / n}\right]$ & 14.458 \\
\hline & & $N$ & 7.237 \\
\hline & & $R^{2}$ & 0.935 \\
\hline & & $S S E$ & 13.277 \\
\hline & \multirow{4}{*}{ Langmuir } & $q_{\max }\left[\mathrm{mg} \cdot \mathrm{g}^{-1}\right]$ & 31.602 \\
\hline & & $b\left[\mathrm{~L} \cdot \mathrm{mg}^{-1}\right]$ & 0.097 \\
\hline & & $R^{2}$ & 0.777 \\
\hline & & SSE & 3.868 \\
\hline \multirow{8}{*}{ 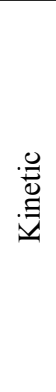 } & \multirow{4}{*}{ pseudo-first order } & $q_{e}\left[\mathrm{mg} \cdot \mathrm{g}^{-1}\right]$ & 29.938 \\
\hline & & $k_{1}\left[1 \cdot \mathrm{min}^{-1}\right]$ & 0.0083 \\
\hline & & $R^{2}$ & 0.982 \\
\hline & & $S S E$ & 4.632 \\
\hline & \multirow{4}{*}{ pseudo-second order } & $q_{e}\left[\mathrm{mg} \cdot \mathrm{g}^{-1}\right]$ & 47.04 \\
\hline & & $k_{2}\left[\mathrm{~g} \cdot \mathrm{mg}^{-1} \cdot \mathrm{min}^{-1}\right]$ & 0.0001 \\
\hline & & $R^{2}$ & 0.977 \\
\hline & & SSE & 5.676 \\
\hline \multirow{2}{*}{\multicolumn{2}{|c|}{ Intra-particle diffusion }} & $k_{\text {int }}\left[\mathrm{mg} \cdot \mathrm{g}^{-1} \cdot \min ^{-0.5}\right]$ & 2.219 \\
\hline & & $R^{2}$ & 0.967 \\
\hline
\end{tabular}

\section{Conclusion}

This has been researched the possible use of building material waste as an adsorbent to benzene. Building material was found to be more effective for removing benzene from the solution; the maximum benzene's adsorption efficiency was $31.601 \mathrm{mg} \cdot \mathrm{g}^{-1}$. The percentage of removal depended strongly on the contact time, the solution's initial $\mathrm{pH}$, and adsorbent dose. Initial $\mathrm{pH}$, contact time, and sorbent dose must be 6 , $1 \mathrm{~h}$ and $1.2 \mathrm{mg}$ per $100 \mathrm{~mL}$ for $C_{o}$ of $300 \mathrm{mg} \cdot \mathrm{L}^{-1}$ and a speed of agitation of $200 \mathrm{rpm}$, respectively, are the best conditions for achieving these effects. Sorption results are well illustrated by the Freundlich model for the interaction of ben- zene-water contaminated with sorbent. Finally, the kinetic process is consistent with the pseudo-second order equation.

\section{References}

Abdulhadi, B., Kot, P., Hashim, K., Shaw, A., Muradov, M. \& Al-Khaddar, R. (2021). Continuous-flow electrocoagulation (EC) process for iron removal from water: experimental, statistical and economic study. Science of the Total Environment, 756(2), 1-16.

Abdulla, G., Kareem, M.M., Hashim, K.S., Muradov, M., Kot, P., Mubarak, H.A., Abdellatif, M. \& Abdulhadi, B. (2020). Removal of iron from wastewater using a hybrid filter. IOP Conference Series: Materials Science and Engineering, 888(1), 012035. https://www. doi.org/10.1088/1757-899X/888/1/012035 
Abdulraheem, F.S., Al-Khafaji, Z.S., Hashim, K.S., Muradov, M., Kot, P. \& Shubbar, A.A. (2020). Natural filtration unit for removal of heavy metals from water. IOP Conference Series: Materials Science and Engineering, 888(1), 012034. https://www.doi. org/10.1088/1757-899X/888/1/012034

Aivalioti, M., Pothoulaki, D., Papoulias, P. \& Gidarakos, E. (2012). Removal of BTEX, MTBE and TAME from aqueous solutions by adsorption onto raw and thermally treated lignite. Journal of Hazardous Materials, 207, 136-146.

Alenazi, M., Hashim, K. S., Hassan, A. A., Muradov, M., Kot, P., \& Abdulhadi, B. (2020). Turbidity removal using natural coagulants derived from the seeds of Strychnos potatorum: statistical and experimental approach. IOP Conference Series: Materials Science and Engineering, 888(1), 012064. https://www. doi.org/10.1088/1757-899X/888/1/012064

Alenezi, A.K., Hasan, H.A., Hashim, K.S., Amoako-Attah, J., Gkantou, M., Muradov, M., Kot, P. \& Abdulhadi, B. (2020). Zeolite-assisted electrocoagulation for remediation of phosphate from calcium-phosphate solution. IOP Conference Series: Materials Science and Engineering, 888(1), 012031. https://www. doi.org/10.1088/1757-899X/888/1/012031

Alhendal, M., Nasir, M.J., Hashim, K.S., Amoako-Attah, J., Al-Faluji, D., Muradov, M., Kot, P. \& Abdulhadi, B. (2020). Cost-effective hybrid filter for remediation of water from fluoride. IOP Conference Series: Materials Science and Engineering, 888(1), 012038. https://www.doi.org/10.1088/1757899X/888/1/012038

Al-Marri, S., AlQuzweeni, S.S., Hashim, K.S., AlKhaddar, R., Kot, P., AlKizwini, R.S., Zubaidi, S.L. \& Al-Khafaji, Z.S. (2020). Ultrasonic-Electrocoagulation method for nitrate removal from water. IOP Conference Series: Materials Science and Engineering, 888(1), 012073. https://www.doi.org/10.1088/1757899X/888/1/012073

Alnaimi, H., Idan, I. J., Al-Janabi, A., Hashim, K.S., Gkantou, M., Zubaidi, S.L., Kot, P. \& Muradov, M. (2020). Ultrasonic-electrochemical treatment for effluents of concrete plants. IOP Conference Series: Materials Science and Engineering, 888(1),
012063. https://www.doi.org/10.1088/1757899X/888/1/012063

Alquzweeni, S.S. \& Alkizwini, R.S. (2020). Removal of cadmium from contaminated water using coated chicken bones with double-layer hydroxide (Mg/Fe-LDH). Water, 12(8), 2303. https://doi.org/10.3390/w12082303

Alyafei, A., AlKizwini, R.S., Hashim, K.S., Yeboah, D., Gkantou, M., Al Khaddar, R., Al-Faluji, D. \& Zubaidi, S.L. (2020). Treatment of effluents of construction industry using a combined filtration-electrocoagulation method. IOP Conference Series: $\mathrm{Ma}$ terials Science and Engineering, 888(1), 012032. https://www.doi.org/10.1088/1757899X/888/1/012032

Aqeel, K., Mubarak, H.A., Amoako-Attah, J., Abdul-Rahaim, L.A., Al Khaddar, R., Abdellatif, M., Al-Janabi, A. \& Hashim, K.S. (2020). Electrochemical removal of brilliant green dye from wastewater. IOP Conference Series: Materials Science and Engineering, 888(1), 012036. https://www.doi.org/10.1088/1757$899 \mathrm{X} / 888 / 1 / 012036$

Bakather, O.Y. (2020). Adsorption of benzene on impregnated carbon nanotubes. Ain Shams Engineering Journal, 11(4), 905-912.

Elsayed, E., Raya, A.D., Mahmoud, S., Anderson, P.A., Elsayed, A. \& Youssef, P.G. (2017). CPO-27 (Ni), aluminium fumarate and MIL-101 (Cr) MOF materials for adsorption water desalination. Desalination, 406, 25-36.

Emamjomeh, M. M., Mousazadeh, M., Mokhtari, N., Jamali, H.A., Makkiabadi, M., Naghdali, Z., Hashim, K.S. \& Ghanbari, R. (2020). Simultaneous removal of phenol and linear alkylbenzene sulfonate from automotive service station wastewater: Optimization of coupled electrochemical and physical processes. Separation Science and Technology, 55(17), 3184-3194.

Emamjomeh, M.M., Kakavand, S., Jamali, H.A., Alizadeh, S.M., Safdari, M., Mousavi, S.E.S., Hashim, K. S. \& Mousazade, M. (2020). The treatment of printing and packaging wastewater by electrocoagulation-flotation: the simultaneous efficacy of critical parameters and economics. Desalination and Water Treatment, 205, 161-174.

Faisal, A.A. \& Naji, L.A. (2019). Simulation of ammonia nitrogen removal from simulated 
wastewater by sorption onto waste foundry sand using artificial neural network. Association of Arab Universities Journal of Engineering Sciences, 26(1), 28-34.

Grmasha, R.A., Al-Sareji, O.J., Salman, J.M., Hashim, K.S. \& Jasim, I.A. (2020). Polycyclic Aromatic Hydrocarbons (PAHs) in urban street dust within three land-uses of Babylon Governorate, Iraq: distribution, sources, and health risk assessment. Journal of King Saud University - Engineering Sciences, 33, 1-18.

Hashim, K., Kot, P., Zubaid, S., Alwash, R., Al Khaddar, R., Shaw, A., Al-Jumeily, D. \& Aljefery, M. (2020). Energy efficient electrocoagulation using baffle-plates electrodes for efficient Escherichia coli removal from wastewater. Journal of Water Process Engineering, 33(20), 101079-101086.

Hashim, K.S., Al-Saati, N.H., Hussein, A.H. \& Al-Saati, Z.N. (2018). An investigation into the level of heavy metals leaching from canal-dreged sediment: a case study metals leaching from dreged sediment. IOP Conference Series: Materials Science and Engineering, 454(1), 012022. https://www.doi. org/10.1088/1757-899X/454/1/012022

Hashim, K.S., Ewadh, H.M., Muhsin, A.A., Zubaidi, S.L., Kot, P., Muradov, M., Aljefery, M. \& Al-Khaddar, R. (2020). Phosphate removal from water using bottom ash: Adsorption performance, coexisting anions and modelling studies. Water Science and Technology, 82(11), 1-17.

Hashim, K.S., Shaw, A., AlKhaddar, R., Kot, P. \& Al-Shamma'a, A. (2021). Water purification from metal ions in the presence of organic matter using electromagnetic radiation-assisted treatment. Journal of Cleaner Production, 280(2), 1-17.

Kadhim, A., Sadique, M., Al-Mufti, R. \& Hashim, K. (2020). Long-term performance of novel high-calcium one-part alkali-activated cement developed from thermally activated lime kiln dust. Journal of Building Engineering, 32, 1-17.

Legrouri, K., Khouya, E., Oumam, M., Hannache, H., Ezzine, M., Fakhi, S. \& Hanafi, N. (2018). Preparation and characterization of activated carbons obtained from molasses by phosphoric acid activation. Applied Journal of Environmental Engineering Science, 4(3), 352-366.
Mohammed, A.H., Hussein, A.H., Yeboah, D., Al Khaddar, R., Abdulhadi, B., Shubbar, A.A. \& Hashim, K.S. (2020). Electrochemical removal of nitrate from wastewater. IOP Conference Series: Materials Science and Engineering, 888(1), 012037. https://www. doi.org/10.1088/1757-899X/888/1/012037

Omran, I.I., Al-Saati, N.H., Hashim, K.S., Al-Saati, Z.N., Patryk, K., Khaddar, R.A., Al-Jumeily, D., Shaw, A., Ruddock, F. \& Aljefery, M. (2019). Assessment of heavy metal pollution in the Great Al-Mussaib irrigation channel. Desalination and Water Treatment, 168, 165-174.

Perrich, J.R. (2018). Activated carbon adsorption for wastewater treatment. Boca Raton, FL: CRC Press.

Salah, Z., Abdulkareem, I.H., Hashim, K.S., Al-Bugharbee, H., Ridha, H.M., Gharghan, S.K., Al-Qaim, F. F., Muradov, M., Kot, P. \& Alkhaddar, R. (2020). Hybridised artificial neural network model with slime mould algorithm: a novel methodology for prediction urban stochastic water demand. Water, 12(10), 1-18.

Salah, Z., Ortega-Martorell, S., Kot, P., Alkhaddar, R.M., Abdellatif, M., Gharghan, S.K., Ahmed, M.S., \& Hashim, K. (2020). A method for predicting long-term municipal water demands under climate change. Water Resources Management, 34(3), 1265-1279.

Zanki, A.K., Mohammad, F.H., Hashim, K.S., Muradov, M., Kot, P., Kareem, M.M. \& Abdulhadi, B. (2020). Removal of organic matter from water using ultrasonic-assisted electrocoagulation method. IOP Conference Series: Materials Science and Engineering, 888(1), 012033. https://www.doi.org/10.1088/1757899X/888/1/012033

Zubaidi, S., Al-Bugharbee, H., Muhsin, Y.R., Hashim, K. \& Alkhaddar, R. (2020). Forecasting of monthly stochastic signal of urban water demand: Baghdad as a case study. IOP Conference Series: Materials Science and Engineering, 888(1), 012018. https://www. doi.org/10.1088/1757-899X/888/1/012018

Zubaidi, S., Ortega-Martorell, S., Al-Bugharbee, H., Olier, I., Hashim, K.S., Gharghan, S.K., Kot, P. \& Al-Khaddar, R. (2020). Urban water demand prediction for a city that suffers from climate change and population growth: Gauteng Province case study. Water, 12(7), 1-18. 


\section{Summary}

A novel application of building demolition waste for removal benzene from aqueous solutions. A novel application of building demolition waste for removal benzene from aqueous solutions. In this research, demolition waste from buildings has been studied for possible use as benzene removal adsorbent from aquatic solution. The effect of adsorbent dosage, contact time, initial benzene concentration, and initial $\mathrm{pH}$ on benzene adsorption capacity have been investigated in the batch adsorption experiments. The adsorption effects initially happened very rapidly and achieved equilibrium within $180 \mathrm{~min}$. Benzene removal was observed to decrease by an increase in the initial concentration of benzene of 300-700 $\mathrm{mg} \cdot \mathrm{L}^{-1}$, an increase in the adsorbent dose of $0.4-2.4 \mathrm{~g}$ per $100 \mathrm{~mL}$, where an optimum adsorbent dose equal to $1.2 \mathrm{~g}$ per $100 \mathrm{~mL}$ was found. The potential of adsorption increases with $\mathrm{pH} 3.0-7.0$ to reach the maximum removal efficiency at $\mathrm{pH}$ 6.0. The findings showed that equilibrium data were adequate- ly adapted and correlated with the Freundlich isotherm models. The average percentage of the removal at room temperature was about $98 \%$. Results suggest that building demolition waste can be used effectively in industrial wastewater treatment for the removal of aromatic hydrocarbon, benzene, as a low-cost option.

\section{Authors' address:}

Saif S. Alquzweeni - corresponding author University of Babylon

College of Engineering

Department of Civil Engineering 40-street, 009647812260838, 51001, Babil Iraq

e-mail: saifalquzweeni@gmail.com

Afrah A. Hassan

Rasha S. Alkizwini

University of Babylon

College of Engineering

Department of Environmental Engineering 80-street, 009647812835911, 51001, Babil Iraq

e-mail: eng.afrah.abood@uobabylon.edu.iq eng.rasha.salah2018@gmail.com 